\title{
SIZE MATTERS: STICKLEBACK SIZE AND INFECTION WITH ARGULUS FOLIACEUS (L., 1758) (BRANCHIURA, ARGULOIDA)
}

BY

\author{
P. D. WALKER ${ }^{1,2,4}$ ), J. HARRIS ${ }^{2}$ ), G. VAN DER VELDE ${ }^{1,3}$ ) and
}

S. E. WENDELAAR BONGA ${ }^{1}$ )

1) Department of Animal Ecology \& Ecophysiology, Institute for Water and Wetland Research, Faculty of Science, Radboud University Nijmegen, Toernooiveld 1, NL-6525 ED Nijmegen, The

Netherlands

2 ) School of Biological Sciences, University of Plymouth, Drake Circus, Plymouth, PL4 8AA, U.K.

3 ) National Museum of Natural History Naturalis, P.O. Box 9517, NL-2300 RA Leiden, The

Netherlands

Parasite loads on fish have been shown to be influenced by the size of the host (Kabata, 1981; Grutter, 1994). The general trend is that a larger host will harbour higher numbers of ectoparasites (Tucker et al., 2002). The reasons for this may be partly related to the hosts age (larger hosts are generally older) with older hosts having had longer to accumulate parasites, and partly related to the surface area of the host as a larger host has a larger surface area making it easier for parasites to locate and attach to them (Kuris et al., 1980, and references therein). This trend has not been tested for branchiuran ectoparasites before.

Crustacean ectoparasites on fish provide an excellent model for studying parasite distribution within a host population due to the relative ease in identifying and counting them. Parasites from the genus Argulus are regarded as the most widespread and problematic parasites in freshwater fish culture (Kearn, 2004; Walker et al., 2004). These parasites have been responsible for significant economic losses in aquaculture (Menezes et al., 1990) and recreational fishery operations (Taylor et al., 2006). Despite this, there are still huge gaps in our understanding of the way in which these parasites interact with their hosts.

Argulus foliaceus (L., 1758), is regarded as non-host-specific and has been recorded from practically every freshwater fish species within its natural range (Stammer, 1959; Kennedy, 1974). Despite the opportunistic nature of this parasite some hosts still appear to be more susceptible than others (Bandilla et al., 2005). The factors influencing the distribution of A. foliaceus within a host population,

\footnotetext{
4 ) e-mail: P.Walker@science.ru.nl 
however, are still poorly studied. In this investigation we analysed a stickleback population from a recreational fishing lake in the south-west of England.

Three-spined sticklebacks, Gasterosteus aculeatus (L., 1758) are commonly found in temperate waterbodies of the northern hemisphere (Wootton, 1976). Because of their role in the food web as both predators and prey they are consequently hosts in many parasite life cycles (Kalbe et al., 2002). As a result, they may also serve as reservoirs for some parasite species, transmitting parasites to other fish residing in the same habitats. Three-spined sticklebacks breed in the warm shallow regions of ponds and lakes (Davies et al., 2004), which are the same regions preferred for egg deposition by A. foliaceus. This will expose sticklebacks to this parasite throughout the breeding season and as such one would expect a high infection intensity and prevalence on this fish species. The authors have previously found one adult male three-spined stickleback with 143 larval $A$. foliaceus attached to it (P. D. Walker, unpubl.). However, juvenile sticklebacks appear to show behavioural changes including an increase in shoaling behaviour in the presence of argulid lice (Poulin, 1999). These changes in behaviour probably reduce the risk of individuals being parasitized.

Three-spined sticklebacks were caught from the littoral regions of the lake using a standard pond net. Upon capture, the standard length of each fish was recorded and the number of attached parasites noted. Statistical analyses were carried out using Quantitative Parasitology 3.0 (QP 3.0: Reiczigel \& Rózsa, 2005) and INSTAT.

Fifty-three sticklebacks were caught varying in length from 13 to $44 \mathrm{~mm}$. Sixteen of the fish were $\leqslant 20 \mathrm{~mm}$ long, only 1 fish was found between 21 and $30 \mathrm{~mm}$ long, and the remaining 36 fish were $>31 \mathrm{~mm}$ long. Thirty of the fish were infected with A. foliaceus, giving a parasite prevalence of $56 \%$ (95\% confidence limits: 42 to $70 \%)$. The mean infection intensity was 7.33 (95\% confidence limits: 5.43 to $9.57 ; \mathrm{n}=30$ ) and the maximum number of lice recorded on an individual fish was 23 . The average length of infected sticklebacks was significantly greater (Mann-Whitney U-test, 2-tailed $P$-value $<0.0001$ ) than that of the uninfected sticklebacks (fig. 1). In addition, all infected fish were found to be more than 30 $\mathrm{mm}$ in length (fig. 2).

The size distribution of the sticklebacks probably reflects two distinct year classes. For many parasite species the infection intensity is often related to the size of the host, with larger hosts generally being older and therefore having had longer to accumulate parasites (Kuris et al., 1980). However, this trend probably does not apply for intermittent parasites such as Argulus species as these parasites frequently leave their hosts throughout their lives. Therefore, the greater number of parasites found on the larger hosts must be attributable to some other factor. 


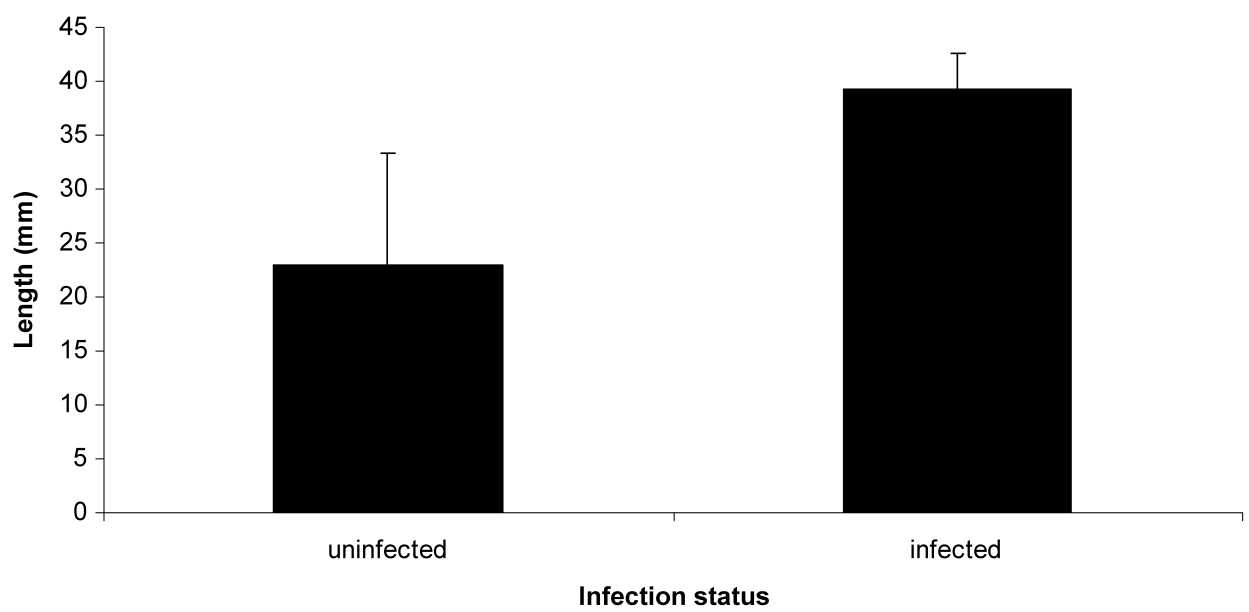

Fig. 1. Mean standard length of Argulus foliaceus (L., 1758) infected $(\mathrm{n}=30)$, and uninfected threespined sticklebacks, Gasterosteus aculeatus $(\mathrm{L} ., 1758)(\mathrm{n}=23)$. Error bars $= \pm 1$ s.d.

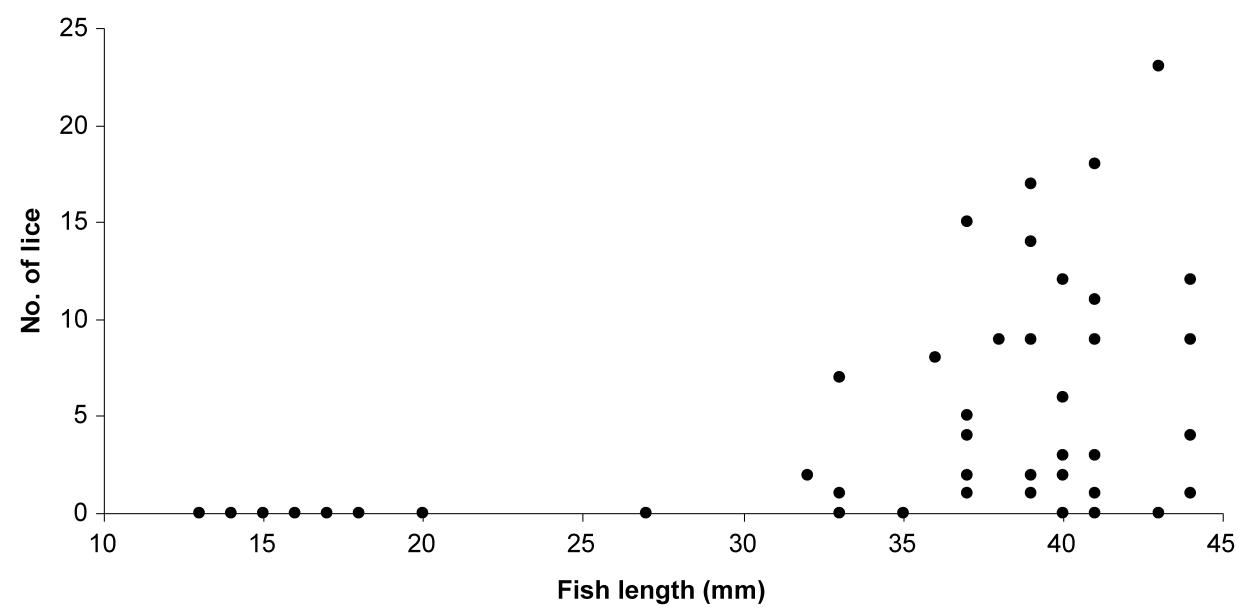

Fig. 2. Scatter plot showing the relation between three-spined stickleback Gasterosteus aculeatus (L., 1758) standard length, and infection intensity of Argulus foliaceus (L., 1758).

Juvenile sticklebacks can and do exhibit parasite avoidance behaviour (Poulin \& FitzGerald, 1988; Dugatkin et al., 1994). Mikheev et al. (2003), observed a similar behavioural trait in juvenile roach, Rutilus rutilus (L., 1758). It is plausible that the lack of parasites on small sticklebacks in this study is a result of parasite avoidance behaviour. It is also plausible that below a certain size threshold Argulus simply does not regard fish as a host and that A. foliaceus is in fact size-selective when locating a suitable host. Poulin \& FitzGerald (1988) proposed that it may be adaptive for Argulus funduli Krøyer, 1863 (incorrectly identified as A. canadensis Wilson, 1916; see Poulin, 1999) to parasitize smaller hosts as larger fish capture 
and eat more parasites. However, our data for A. foliaceus and three-spined sticklebacks do not appear to support this hypothesis.

In conclusion, our study demonstrates a possible size-based difference in susceptibility amongst three-spined sticklebacks. We hypothesize that this susceptibility is caused by behavioural interplays between the sticklebacks and A. foliaceus, although parasite-induced mortality of very small fish cannot be ruled out. Future studies involving the interactions between Argulus foliaceus and three-spined sticklebacks are required to fully elucidate the reasons for our observations.

\section{ACKNOWLEDGEMENTS}

Thanks are extended to the owners of Mile Mead fisheries for allowing the authors to conduct this investigation on their premises. The authors acknowledge the financial support of the European Community's Improving Human Potential Program under contract [HPRN-CT-2001-00241], [PARITY]. This is CWE publication number 489 .

\section{LITERATURE CITED}

Bandilla, M., T. Hakalahti, P. J. Hudson \& E. T. Valtonen, 2005. Aggregation of Argulus coregoni (Crustacea: Branchiura) on rainbow trout (Onchorhynchus mykiss): a consequence of host susceptibility or exposure? Parasitology, 130: 169-176.

Davies, C., J. Shelly, P. Harding, I. Mclean, R. Gardiner \& G. Peirson, 2004. British freshwater fishes - the species and their distribution: 1-175. (Harley Books, Essex).

Dugatkin, L. A., G. J. FitzGerald \& J. Lavoie, 1994. Juvenile three-spined sticklebacks avoid parasitized conspecifics. Environ. Biol. Fish., 39: 215-218.

GRUTTER, A. S., 1994. Spatial and temporal variations of the ectoparasites of seven reef fish species from Lizard Island and Heron Island, Australia. Mar. Ecol. Progr. Ser., 115: 21-30.

Hoffman, G. L., 1977. Argulus, a branchiuran parasite of freshwater fishes. U.S. Fish and Wildlife Service, Fish Diseases Leaflet, 49: 9.

KABATA, Z., 1981. Copepoda (Crustacea) parasitic on fishes: problems and perspectives. Advances in Parasitology, 19: 1-71.

Kalbe, M., K. M. WeGner \& T. B. H. ReusCH, 2002. Dispersion patterns of parasites in 0+ year three-spined sticklebacks: a cross population comparison. Journ. Fish Biol., 60: 1529-1542.

KEARN, G. C., 2004. Leeches, lice and lampreys: a natural history of skin and gill parasites of fishes: 1-432. (Springer, Dordrecht).

KENNEDY, C. R., 1974. A checklist of British and Irish freshwater fish parasites with notes on their distribution. Journ. Fish Biol., 6: 613-644.

Kuris, A. M., A. R. Blaustein \& J. J. Alio, 1980. Hosts as islands. The American Naturalist, 116: $570-586$.

Menezes, J., M. A. Ramos, T. G. Pereira \& A. Moreira da Silva, 1990. Rainbow trout culture failure in a small lake as a result of massive parasitosis related to careless introductions. Aquaculture, 89: 123-126. 
Mikheev, V. N., A. F. Pasternak \& E. T. Valtonen, 2003. How do fish ectoparasites Argulus spp. (Crustacea: Branchiura) match with their hosts at the behavioural and ecological scales? Zhurnal Obshchei Biologii, 64: 238-247.

Poulin, R., 1999. Parasitism and shoal size in juvenile sticklebacks: conflicting selection pressures from different ectoparasites? Ethology, 105: 959-968.

Poulin, R. \& G. J. FitzGERALD, 1988. Water temperature, vertical distribution, and risk of ectoparasitism in juvenile sticklebacks. Canadian Journ. Zool., 66: 2002-2005.

ReICZIGEL, J. \& L. RóZSA, 2005. Quantitative parasitology 3.0. (Budapest; distributed by the authors).

Rhaman, M., 1996. Effects of a freshwater fish parasite, Argulus foliaceus Linn. infection on common carp, Cyprinus carpio Linn. Bangladesh Journ. Zool., 24: 57-63.

STAMMER, H. J., 1959. Beiträge zur Morphologie, Biologie und Bekämpfung der Karpfenläuse. Zeitschrift für Parasitenkunde, 19: 135-208.

Taylor, N. G. H., C. Sommerville \& R. Wooten, 2006. The epidemiology of Argulus spp. (Crustacea: Branchiura) infections in stillwater trout fisheries. Journ. Fish Dis., 29: 193-200.

TuCKer, C. S., C. Sommerville \& R. Wooten, 2002. Does size really matter? Effects of fish surface area on the settlement and initial survival of Lepeophtheirus salmonis, an ectoparasite of Atlantic salmon Salmo salar. Dis. aquat. Org., 49: 145-152.

Walker, P. D., G. Flik \& S. E. WendelaAR BONGA, 2004. The biology of parasites from the genus Argulus and a review of the interactions with its host. Symposia of the Society for Experimental Biology, 55: 107-129.

WootTON, R. J., 1976. The biology of the sticklebacks: 1-387. (Academic Press, London). 